\title{
10 Lições sobre Bourdieu
}

MONTEIRO, José Marciano. 10 Lições sobre Bourdieu. Petrópolis: Vozes, 2018.

\section{Introdução}

Em 10 Lições sobre Bourdieu, José Marciano Monteiro² tem por objetivo divulgar a produção científica de Bourdieu a estudantes e leitores iniciantes do autor. A obra de Bourdieu apresenta significativa contribuição para o campo das humanidades, sendo amplamente citada em pesquisas contemporâneas no campo das Ciências Sociais, Educação, Artes e Cultura. Considerando seu trabalho sobre o sistema educacional francês, Bourdieu pode ser considerado um dos autores pioneiros no campo da Sociologia da Educação, sendo precedido por pensadores como Durkheim e Parsons. Dessa maneira, apresenta-se a resenha do livro de José Marciano Monteiro, segmentado em dez capítulos que serão descritos a seguir.

\section{Sobre a obra}

O primeiro capítulo apresenta a biografia de Pierre Félix Bourdieu. Percorre sua infância na região rural francesa de Denguin, seu período de serviço militar na Argélia, sua carreira como professor, chegando à data de seu falecimento, em 23 de janeiro de 2002, aos 79 anos de idade.

O segundo capítulo é dedicado à teoria da prática ou praxiologia. Bourdieu divide os modos de conhecimento do mundo social em fenomenológico, com foco na captura da experiência; estruturalista, que promove uma ruptura com a experiência imediata, buscando compreender as estruturas objetivas do fenômeno, sem se preocupar com as estratégias adotadas pelos indivíduos a partir de suas trajetórias; e praxiológico, que concebe a ação social como resultado da relação entre estrutura objetiva e estrutura subjetiva, ambas mediadas pelo habitus (estruturas internalizadas sob a forma de disposições que orientam a ação). Dessa maneira, ultrapassa o subjetivismo da fenomenologia (que levaria à ilusão de que o indivíduo age sobre

1 Doutoranda pelo Programa de Pós-graduação em Educação: conhecimento e Inclusão social da Universidade Federal de Minas Gerais. Mestre em Educação pela Universidade Federal do Rio de Janeiro. Professora da Rede Estadual de Educação do Rio de Janeiro. E-mail: albuquerquerlf@gmail.com ORCID iD: https://orcid.org/0000-0001-9240-6144

2 José Marciano Monteiro é doutor em Ciências Sociais e professor adjunto da Universidade Federal de Campina Grande (UFCG), sendo coordenador do Núcleo de Estudos sobre Elites, Famílias e Desigualdades (NEFADE/CNPQ) na mesma instituição. É autor dos livros A Política como negócio de família. Para uma sociologia política das elites e do poder político familiar, pela editora LiberArs (2017) e de 10 Lições sobre Bourdieu, pela editora Vozes (2018). 
escolhas autônomas, desconsiderando as condições sociais e objetivas que possibilitam a ação) e o objetivismo do estruturalismo. Na praxiologia a ação é construída pelas estruturas objetivas do mundo social e incorporada pelos agentes a partir de seu contexto e de sua posição no espaço social.

No terceiro capítulo é apresentada a contribuição de Bourdieu para a metodologia de produção do conhecimento científico a partir dos princípios da ruptura, não consciência e primazia das relações. O princípio da ruptura relaciona-se à ruptura com a ilusão do saber imediato e à necessidade de utilização de ferramentas de análise metodológica. O princípio da não consciência compreende que os elementos que explicam a vida social não são percebidos pela consciência particular dos indivíduos, havendo causas e estruturas profundas que orientam os comportamentos sociais. $\mathrm{O}$ princípio da primazia das relações compreende que um fenômeno está sempre inserido em um sistema de relações históricas e sociais que permite e orienta a sua manifestação, não se reduzindo às subjetividades. Para Bourdieu, o objeto da sociologia precisa ser conquistado, com a superação do saber imediato; construído, em um processo de relação entre problemática e metodologia; e constatado, a partir da síntese analítica das duas etapas anteriores.

O quarto capítulo apresenta a sociedade como espaço estruturado em função das distâncias sociais que separam os agentes. A quantidade de capital acumulado define aqueles que se localizam no polo dominante ou no polo dos dominados. O espaço social (constituído pelos campos cultural, econômico, político, educacional, científico, entre outros) é onde os agentes irão atuar de acordo com seu quantum de capital acumulado, suas disposições internalizadas e sua posição social. Por sua vez, os campos se constituem como microcosmos em que os agentes atuam. Essa atuação se relaciona com as trajetórias dos agentes (aspectos subjetivos), sua posição social e suas disposições internalizadas que se manifestam através do habitus. Monteiro (2018) aponta que mesmo as estruturas objetivas do campo são incorporadas pelos agentes, também se manifestando na forma de habitus, ou seja, em esquemas de percepção que orientam as ações. Ao incorporar o habitus de um determinado campo, o agente se encontraria em condições de disputar os capitais dentro desse campo. Para além da manutenção da posição social e de disputas de capitais, os agentes atuam pelo controle de produção de bens escassos dentro de um campo, construindo mecanismos de distinção (BOURDIEU, 2007).

O quinto capítulo resgata o conceito de habitus, já introduzido anteriormente. O habitus, nas palavras de Bourdieu, são "sistemas de disposições duráveis e transponíveis, estruturas estruturadas predispostas a funcionar como estruturas estruturantes" (BOURDIEU, 2009, p. 87). Constitui-se por esquemas de pensamento e percepção que orientam a ação dos agentes a partir de sua posição no espaço social e de suas disposições internalizadas. O habitus pode se traduzir em ethos - valores e práticas culturais coletivas incorporadas nas ações dos agentes - e em hexis corporal - posturas, comportamentos e disposições incorporadas e manifestas através dos corpos dos agentes. Dessa maneira, as distâncias no espaço social entre as classes dominantes e dominadas podem ser observadas nas posturas corporais dos agentes, na valorização de determinadas práticas relacionadas à alimentação e ao vestuário, no acesso e na importância de bens vinculados ao corpo, às artes e à cultura.

O sexto capítulo apresenta a teoria dos capitais. Dois tipos de capitais estruturariam a sociedade contemporânea: capital econômico e capital cultural. O primeiro engloba o patrimônio material e todas as manifestações de recursos financeiros. $\mathrm{O}$ segundo pode se manifestar em três estados: capital cultural incorporado, que compreende a incorporação de valores transmitidos pela família e pelas instituições; capital cultural objetivado, que é o acúmulo de bens materiais relacionados à cultura legitimada pela classe dominante; e capital cultural institucionalizado, o acúmulo de instrução legitimada institucionalmente. Bourdieu, no que chamou de economia das práticas dos bens simbólicos, identifica como capital social as redes de relações duráveis que podem ser reconhecidas institucionalmente, como o casamento. Já o capital simbólico seria legitimado pelo reconhecimento, nas formas como os agentes legitimam os elementos de diferenciação de 
uma classe ou de outros agentes. Por sua vez, o capital político comporia as redes de relações e de reconhecimento que legitimam agentes à condição de representantes de um dado grupo.

O sétimo capítulo relaciona o conceito de habitus ao corpo socializado. O corpo dos agentes é uma instância do social incorporado. Nesse sentido, o corpo se transforma em linguagem sobre a qual se lê o mundo e se é lido. A cultura também é internalizada nos corpos, sendo objetivada em práticas que se relacionam com a posição social dos agentes e suas condições materiais de existência. Dessa maneira, a cultura legitimada é reconhecida não apenas pela classe dominante, mas pelas instituições educacionais que legitimam o capital cultural institucionalizado. Assim, as desigualdades escolares podem ser explicadas pelas diferenças de origens e de oportunidades sociais, uma vez que a escolarização exige habilidades e competências relacionadas ao habitus da classe dominante.

No oitavo capítulo, o poder simbólico é apresentado como uma dimensão que se integra às disposições dos agentes. O poder simbólico constrói uma realidade edificada pela ordem simbólica entre dominantes e dominados. Essa ordem, construída através do uso de mecanismos de coerção que se manifestam como violência simbólica, reafirma a reprodução e manutenção da ordem social.

No nono capítulo, é apresentada a metáfora do jogo e os conceitos de estratégia e senso prático para explicar a lógica das ações construídas pelos agentes no espaço social. Bourdieu se contrapõe ao conceito de regra utilizado pelos estruturalistas ao considerar que as ações dos agentes não se dão de maneira calculada e mecânica. Elas seriam fruto de disposições incorporadas que se relacionam com a posição social do agente e seu quantum de capital acumulado. Os agentes orientariam suas ações em relação aos outros agentes, de acordo com o sentido do jogo. Ou seja, de acordo com as regras e valores de dado campo. Um senso prático, operacionalizado pela lógica da prática, orientando as ações dos agentes. A partir da metáfora do jogo e dos conceitos de estratégia e senso prático, Bourdieu se opõe às teorias estruturalistas (como a teoria da escolha racional que universaliza a ação dos agentes pelo princípio da racionalização).

O décimo capítulo resgata as principais teorias de Bourdieu tratadas nas lições anteriores e o apresenta enquanto um sociólogo que se dedicou à denúncia da manutenção das desigualdades sociais através do uso da violência simbólica.

\section{Síntese}

10 lições sobre Bourdieu contribui com a literatura do campo científico das humanidades sintetizando a vasta e complexa produção de um dos principais autores das Ciências Sociais. Ressalta-se a atualidade de seu pensamento para tratar fenômenos contemporâneos. Por exemplo, a atual oferta de atividades pedagógicas não presenciais na Educação Básica, em virtude da COVID19, pode se caracterizar como um exemplo de processo de produção dos excluídos do interior (NOGUEIRA; CATANI, 2007). O imperativo das desigualdades se manifesta associado ao acesso aos meios digitais de comunicação via internet. Ao passo que surge a demanda por novas formas de organização para garantia do acesso à educação, é preciso questionar a universalidade dos métodos aplicados com vistas a esse fim. Estudos como o de Ernica e Setubal (2019) apontam que variáveis de origem social como nível socioeconômico familiar, escolarização materna, gênero e raça do aluno estariam fortemente associadas ao seu desempenho (ERNICA; SETUBAL, 2019, p. 6). De acordo com o Observatório Social da COVID-19 (ESTADO DE MINAS GERAIS, 2020), 17 milhões de residências nacionais (20\% do total de residências brasileiras), nas quais vivem 7 milhões de estudantes, não possuem acesso à internet. Ainda que de fundamental necessidade considerando a conjuntura imposta pela propagação da COVID-19, a adoção do ensino remoto emergencial precisa estar vinculada ao debate sobre o acesso e habilidade de uso dessas ferramentas pelos alunos das distintas redes de ensino. Nesse sentido, Bourdieu auxilia a problematizar a situação daqueles que, 
ainda que em um mesmo nível de escolaridade, possuem acessos tão desiguais a ferramentas que se somam ao seu processo de escolarização.

\section{Referências}

BOURDIEU, Pierre. A distinção: crítica social do julgamento. Porto Alegre: Zouk, 2007.

BOURDIEU, Pierre. O senso prático. Petrópolis: Vozes, 2009.

ERNICA, Maurício; SETUBAL, Maria Alice. IDEA: indicador de desigualdades e aprendizagens. Revista Periferias, Rio de Janeiro, v. 2, p. 1-10, 2019. Disponível em: http://revistaperiferias.org/materia/idea-o-direito-de-todos-a-educacao-de-qualidade/?pdf=2316. Acesso em: 07 abr. 2020.

MAAKAROUN, Bertha. Domicílios sem internet sofrem os impactos do isolamento social. In: Estado de Minas Gerais, Minas Gerais, 12 abr. 2020. Disponível em: https://www.em.com.br/app/noticia/gerais/2020/04/12/interna_gerais,1137796/ domicilios-sem-internet-sofrem-os-impactos-do-isolamento-social.shtml. Acesso em: 06 maio 2020.

MONTEIRO, José Marciano. 10 Lições sobre Bourdieu. Petrópolis: Vozes, 2018.

NOGUEIRA, Maria Alice; CATANI, Afrânio (org.). Escritos de Educação. 9. ed. Petrópolis: Vozes, 2007.

Data de submissão: 08/12/2020

Data de aceite: 17/02/2021 